Water Pollution XIV 145

\title{
EFFECT OF INTERNAL RECIRCULATION ON REACTOR MODELS IN WASTEWATER TREATMENT
}

\author{
TAMAS KARCHES \\ Institute of Water Supply and Environmental Engineering, National University of Public Service, Hungary
}

\begin{abstract}
Application of mass balance models are widespread in designing wastewater treatment processes, where the emphasis is on the biokinetics and transport processes of the biomass. Reactor hydrodynamics is often idealised applying completely stirred tank reactor (CSTR) or plug flow reactor (PFR) based models. If internal recirculation (IR) is required to be applied for pre-denitrification, these models predict the mass transfer appropriately, but hydrodynamics are not simulated and thus the reactor models remain unchanged. In this research the effect of IR on reactor models was investigated by introducing virtual reactor number applied in the simulation system. GPS-X 6.5 commercial tool was used to perform the calculations and the model was calibrated by field measurement. After the evaluation of the results it could have been seen that in basins with plug flow the application of IR did not modify the reactor model significantly, whereas in CSTRs the virtual reactor numbers shall be modified.
\end{abstract}

Keywords: internal recirculation, mass balance modelling, reactor models, wastewater treatment.

\section{INTRODUCTION}

Wastewater treatment technologies are responsible for degradation of organic materials and nutrients in order to reduce the pollutant load of the receiving water body. Treatment stages can be separated into mechanical, biological, tertiary and quaternary treatment. Basically the first two stages are enough to meet effluent quality requirements, but sometimes higher degree of treatment is necessary, e.g. removal of hormones [1]. Conventional technologies apply suspended biomass, which is a group of specific microorganism flocs. Success of biological treatment is based on the floc formulation mechanisms, the stability of the cells and re-flocculation of the detached material [2]. These flocks should be evenly distributed within the reactor volume having approximately $3.5-4.5 \mathrm{~g} / \mathrm{L}$ concentration in activated sludge system.

Design of wastewater treatment process formulates mass balance equations of the main wastewater constituents consisting process kinetics, but hydrodynamic conditions are generally simplified. Idealised reactor models (e.g. CSTR: Completely Stirred Tank Reactor or PFR: Plug Flow Reactor) cannot capture the actual flow conditions of the biological reactor leading discrepancies between the calculated and measured data. Hydrodynamics directly influences the process performance; therefore the knowledge of the flow field is necessary for evaluation of a technology or process. For example, the removal of organic matter requires different flow conditions compared to nitrogen removal [3].

Improvement of the reactor model can be achieved by applying RTD (Residence Time Distribution) technique and with the help of a tracer the reactor flow regime can be determined [4]. The exit age distribution of a tracer gives information on hydraulic residence time and thus the dead-zones and hydraulic short cuts could be revealed. Furthermore, the tank-in-series model could be extended as a subset of the gamma distribution and it removes the problem of quantisation, if the reactor number tends to one [5]. While tank-in-series model has no limitation, the axial dispersion model is sensitive to the boundaries. For a high dispersive system with closed boundaries, a combination of the tank-in-series and axial dispersion model can be introduced [6]. 
Internal recirculation (IR) aiming nitrate transport from aerobic to anoxic reactor could have effect on reactor hydraulics since the discharge may vary from two to four times of the plant influent flow. IR is responsible for denitrification, but as a side effect the less concentrated influent could nitrify at increased efficiency due to dilution [7] and improve the oxygen transfer [8]. Due to presence of the IR (and also the returned activated sludge) tracer tests are difficult to interpret; for the determination of longitudinal dispersion empirical formulae are used [9]. In a system with IR the exit age distribution gained by RTD analysis is different compared to a system without recirculation. The initial part of the curve has a periodicity with decaying amplitude the rest show exponential decay with a long tail indicating the entrapped tracer in the recycle stream [5].

Generally, in process design tools the reactor models have limited capacity, fine tuning is achieved by manual adjustments by setting the reactor number, which is not necessarily the actual reactor number, just a virtual mean to reflect the actual hydrodynamic behaviour of the basin. In this research the effect of IR on tank-in-series reactor model is investigated with the aim of determining the virtual reactor number difference caused by introducing IR. Section 2 describes the methodology used, Section 3 details the results achieved and Section 4 summarizes the research.

\section{MATERIAL AND METHODS}

In this research a 1 MLD Wastewater Treatment Plant (WWTP) was investigated. Chemical oxygen demand (COD) of the average plant influent was $610 \mathrm{mg} / \mathrm{L}$, the total suspended solid (TSS) was $345 \mathrm{mg} / \mathrm{L}$, the total Kjeldahl nitrogen (TKN) - organic and ammonium-nitrogen - was $92 \mathrm{mg} / \mathrm{L}$, whereas the total phosphorus was $14 \mathrm{mg} / \mathrm{L}$ in the raw sewage. The minimum wastewater temperature of $15^{\circ} \mathrm{C}$ was assumed during the simulation. Effluent quality requirements were the following: COD: $125 \mathrm{mg} / \mathrm{L}, \mathrm{BOD}_{5}: 30 \mathrm{mg} / \mathrm{L}$, TSS: $35 \mathrm{mg} / \mathrm{L}, \mathrm{TN}: 20$ $\mathrm{mg} / \mathrm{L}, \mathrm{TP}: 2 \mathrm{mg} / \mathrm{L}$. To achieve the TN limit, full nitrification was required.

Biokinetic modelling was used to predict the plant performance under various operational conditions. The calculations were performed with GPS-X 6.5 commercial software and the process was simulated with ASM2d model, which is a type of Activated Sludge Model family solving 21 transport equations for the model components. The model approach gives back the results of the processes of organic degradation and nutrient $(\mathrm{N}, \mathrm{P})$ removal accurately if the raw sewage originates from municipal source, $\mathrm{pH}$ neutral and the temperatures is in the range of $10-25^{\circ} \mathrm{C}[10]$.

Mathematical modelling is based on the mass transport equation of the model components (state or composite variables). The fate of the component is determined by the flow (reactor model) and reaction kinetics, which can be further decompose to biokinetic process groups such as degradation of organic matter and nutrient elimination. Each process can be described by the reaction rates of sub-processes and applying stoichiometric constants. In other words, a certain process kinetics can be composed by sum of the weighted model variables, where the weighting factors are the process rates. Only one example process of the mathematical description is shown, the heterotrophic growth, the rest can be found in literature [10]. The process rate of this process is the following:

$$
\mu_{H} \cdot \frac{D O}{K_{H, O 2}+D O} \cdot \frac{S S}{K_{H, S S}},
$$

where:

$\mu_{\mathrm{H}}$ : maximum specific growth rate $[1 / \mathrm{d}]$,

DO: dissolved oxygen concentration $[\mathrm{g} / \mathrm{L}]$, 
$\mathrm{K}_{\mathrm{H}, \mathrm{O} 2}$ : half-saturation coefficient of oxygen $[\mathrm{g} / \mathrm{L}]$,

SS: soluble substrate concentration $[\mathrm{g} / \mathrm{L}]$,

$\mathrm{K}_{\mathrm{H}, \mathrm{Ss}}$ : half-saturation coefficient of soluble substrate $[\mathrm{g} / \mathrm{L}]$,

$\mathrm{X}_{\mathrm{H}}$ : heterotrophic biomass concentration $[\mathrm{g} / \mathrm{L}]$.

The transport equation for the soluble solid uses the aerobic heterotrophic yield $\left(\mathrm{Y}_{\mathrm{H}}\right)$ as follows:

$$
\frac{d S S}{d t}=\left(-\frac{1}{Y_{H}}\right) \cdot \mu_{H} \cdot \frac{D O}{K_{H, O 2}+D O} \cdot \frac{S S}{K_{H, S S}} \cdot X_{H}
$$

The heterotrophic biomass growth is described by the following equation:

$$
\frac{d X_{H}}{d t}=(+1) \cdot \mu_{H} \cdot \frac{D O}{K_{H, O 2}+D O} \cdot \frac{S S}{K_{H, S S}} \cdot X_{H} .
$$

The oxygen consumption can be determined:

$$
\frac{d D O}{d t}=\left(1-\frac{1}{Y_{H}}\right) \cdot \mu_{H} \cdot \frac{D O}{K_{H, O 2}+D O} \cdot \frac{S S}{K_{H, S S}} \cdot X_{H}
$$

As the eqns (2) and (3) show parallel to biomass growth the soluble solid concentration decreases, which consumes oxygen. The process equations of the autotrophic biomass, the nutrient removal (chemical and bioP) can be found in [10]. In ASM2d there are more than 60 conversional and stoichiometric model parameters in different groups: yields, halfsaturation coefficients, process rate coefficients and also can be found in the above cited source [10]. The partial differential equations are solved using numerical solver built in GPSX 6.5 software environment and the calculation follows the Runge-Kutta-Fehlberg method.

Process scheme of the plant and the model layout can be seen in Fig. 1, which shows the unit processes and the connectivity between them, where each line represents a mass flow. Raw wastewater discharges to the pre-treatment units including coarse, fine screens and grit chamber. Then the water is pumped to an equalisation tank, which allows the continues feed to the biological basins when it is required. Biological treatment consists of anoxic and aerobic compartments.

The biological treatment follows the pre-denitrification process, the Modified LudzackEttinger (MLE) configuration, which is designed to use nitrate produced by the aeration zone as an oxygen source for facultative bacteria in the breakdown of raw wastewater in the anoxic basin [11]. Phase separation of sludge and treated wastewater takes place in a clarifier. Some part of the sludge (WAS) goes to sludge management for volume reduction. During these processes centrate and filtrate streams are directed back to the biological reactor.

Fig. 1 also shows the model layout, where the raw wastewater discharges directly to the biological reactors. This could be an acceptable approach since pre-treatment units do not have effect on the observed parameters e.g. COD, BOD, TN and the continuous flow setup can be done under the process unit labelled as Influent in the model layout. The compartment number of the biological tanks has to be set a priori. Although the layout does not reflect how many sub-volumes are set, thus it cannot be seen in Fig. 1, but it is used in the calculations. It also can be observed that four different kinds of recycle streams reach the anoxic tank: recycled sludge (RAS), IR, centrate and filtrate from sludge line. 

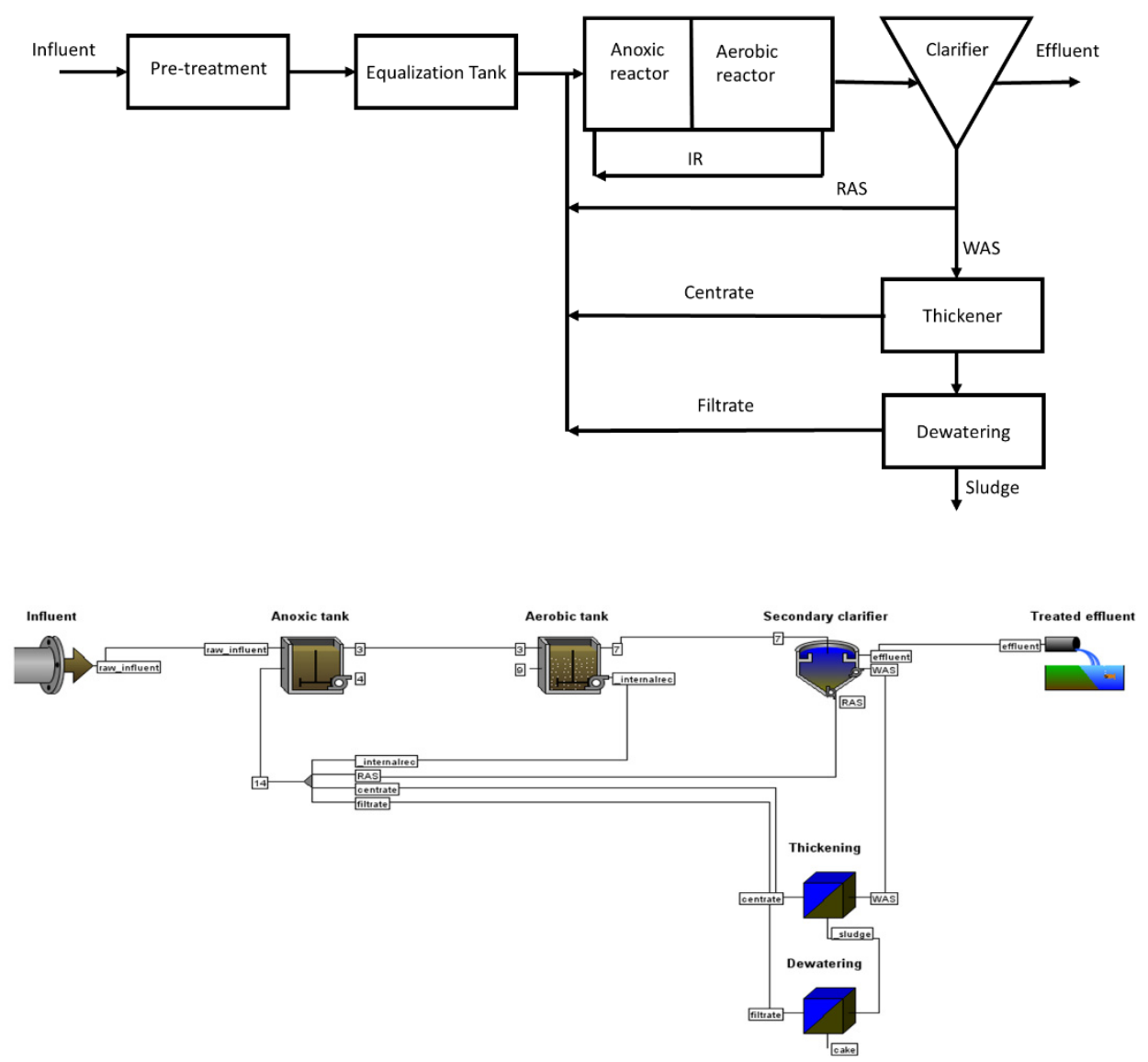

Figure 1: Process scheme of the plant (above); biokinetic model layout (below).

As it is mentioned the reactor numbers used in anoxic and aerobic compartments can be set in the model easily and all of the sub-volumes behave like CSTRs, but in the physical plant this kind of cascading requires that the basin is built in such a way that real well-mixed zones are created. In order to ensure the proper mixing of these sub-zones baffle walls should be applied with alternating position of cross flow section (bottom openings are followed by openings at the top and top openings are followed by openings at the bottom).

Starting point of the simulation was the influent characterization; the determination of chemical oxygen demand (COD) fractions, which were the following: (i) particulate slowly biodegradable $\left(\mathrm{X}_{\mathrm{b}}\right)$, (ii) particulate non-biodegradable $\left(\mathrm{X}_{\mathrm{i}}\right)$, (iii) soluble biodegradable $\left(\mathrm{S}_{\mathrm{b}}\right)$ or (iv) inert soluble $\left(\mathrm{S}_{\mathrm{i}}\right)$ [12]. The removal of latter one would require chemicals to be added since it is non-biodegradable and phase separation cannot be used for soluble matter. The fractionation can be done using laboratory measurements (e.g. NUR test [13]) or empirically using typical ratios for a certain geography. The average value of COD was $610 \mathrm{mg} / \mathrm{L}$, from which the soluble content was $160 \mathrm{mg} / \mathrm{L}$ and the particulate fraction was $450 \mathrm{mg} / \mathrm{L}$ respectively. After influent characterization process the following COD fractions were determined: $X_{b}=368 \mathrm{mg} / \mathrm{L}, X_{\mathrm{i}}=80 \mathrm{mg} / \mathrm{L}, \mathrm{S}_{\mathrm{b}}=130 \mathrm{mg} / \mathrm{L}, \mathrm{S}_{\mathrm{i}}=32 \mathrm{mg} / \mathrm{L}$. Organic content of the suspended solid was set by using VSS/TSS (VSS: Volatile Suspended Solid, TSS: Total 
Suspended Solid) ratio, which had a high value of 0.85. Particulate COD and VSS ratio was 1.55 (literature value for municipal wastewater is: 1.4-2.1 [14]).

After the COD fractionation and the influent setup, biological model parameters were calibrated in order to achieve a good agreement between the model data and the measurements. Calibration of models can be undertaken at various levels based on the actual purpose. There is no consensus on the good practice of calibration process [15]. The limited experience available regarding ASM2-type model calibration results that it could be calibrated based on logical step-wise procedure by changing the lowest number of parameters as possible. Based on the abundant number of parameters available it could be seen that the system has a high degree of freedom, but actually it is reduced in practice, where many couplings among these parameters exist.

Steady-state calibration process was performed by adjusting parameters to match the effluent TSS, COD and $\mathrm{NH}_{4}-\mathrm{N}$ values. Volume weighted 24-hour composite samples were taken from the influent and effluent of each reactor for a 7-day period. From the measurement period it can be seen that the system was in quasi steady-state condition reaching a stable level of biomass inventory. DO probes were installed in each reactor. The measurement data are reconciled, plausibility checks were carried out checking the quality of the measurement (e.g. unrealistic values, ratios not in the acceptable ranges).

These composite values do not reflect the diurnal pattern of the incoming wastewater load, but it is satisfactory for a non-dynamic calibration. As diffusion limitation in the flocs due to the high shearing of turbulence was not observed and the DO concentration was higher than $2 \mathrm{mg} / \mathrm{L}$ in all compartments thus oxygen also not limited the process, the heterotrophic biomass calibration was based on biomass kinetics (yield and decay). Similarly, the autotrophic calibration could be based on several parameters depending on the limiting factors. In our case the ammonium-nitrogen and oxygen values are higher than the saturation coefficient, the ammonia-oxidiser yield shall be changed. More advanced calibration process was not available based on the measurement data and as the IWA TG suggests [16] with lack of data the remaining parameters shall be untouched. With the help of the calibrated model scenarios with various compartment number were simulated and the effect of IR was investigated. The results are detailed in Section 3.

\section{RESULTS}

Applying the influent wastewater parameters and calculation methodology described in Section 2 the calibration and process sizing were performed. In the calibration process most of the stoichiometric and kinetic parameters are remained the same as the default value of ASM2d model built in GPS-X 6.5. Small adjustments were done in case of aerobic heterotrophic yield on soluble substrate $\left(\mathrm{Y}_{\mathrm{h}}\right)$, aerobic heterotrophic decay rate $\left(\mathrm{k}_{\mathrm{dec}, \mathrm{h}}\right)$ and ammonia-oxidiser yield $\left(\mathrm{Y}_{\mathrm{NH} 3}\right)$. Maximum specific growth rates and saturation coefficients are not changed. The adjustment results can be seen in Table 1. Biomass yields are slightly increased and decay heterotrophic biomass decay rate is slightly decreased.

Table 1: Model calibration results.

\begin{tabular}{|l|c|c|c|}
\hline Parameter & $\begin{array}{c}\text { Default } \\
\text { value }\end{array}$ & $\begin{array}{c}\text { Adjusted } \\
\text { value }\end{array}$ & Unit \\
\hline Aerobic heterotrophic yield $\left(\mathrm{Y}_{\mathrm{h}}\right)$ & 0.66 & 0.72 & $\mathrm{gCOD} / \mathrm{gCOD}$ \\
\hline $\begin{array}{l}\text { Aerobic heterotrophic decay } \\
\text { rate }\left(\mathrm{k}_{\mathrm{dec}, \mathrm{h}}\right)\end{array}$ & 0.62 & 0.57 & $1 / \mathrm{d}$ \\
\hline Ammonia-oxidiser yield $\left(\mathrm{Y}_{\mathrm{NH} 3}\right)$. & 0.18 & 0.21 & $\mathrm{gCOD} / \mathrm{gN}$ \\
\hline
\end{tabular}


Mixed Liquor Suspended Solid (MLSS) concentration in the biological reactor was 3.5 $\mathrm{g} / \mathrm{L}$ and the dissolved oxygen (DO) concentration was $2.5 \mathrm{mg} / \mathrm{L}$. The wasted sludge flow (QwAs) was $20 \mathrm{~m}^{3} / \mathrm{d}$ with a dry solid concentration of $0.67 \%$. The calculated aerobic sludge retention time (SRT) was 7.2 days which indicates full nitrification at $15^{\circ} \mathrm{C}$. The recirculated sludge flow was $1000 \mathrm{~m}^{3} / \mathrm{d}$, whereas the internal recirculation flow from the last aerobic reactor to the first anoxic reactor was $2000 \mathrm{~m}^{3} / \mathrm{d}$.

In the full scale plant the aerobic reactor had only one compartment with a volume of $350 \mathrm{~m}^{3}$ and the following dimensions: depth: $5 \mathrm{~m}$, width: $4.5 \mathrm{~m}$ and the length: $15.6 \mathrm{~m}$. The anoxic volume ratio was 0.3 . It was observable that it cannot be a CSTR since two submersible mixers were installed to help mixing and provide even distribution of the MLSS in the tank creating at least two circulating flow zones, therefore the total aerobic volume was divided into two equal sub-volumes in the model by default. Table 2 shows the basic influent and effluent parameters of the pilot plant and the model results. $\mathrm{TKN}=\mathrm{TN}$ as there is no detectable nitrite and nitrate-nitrogen in the influent. There is a good agreement between the model results and the measured effluent.

As the calibration was accepted various model scenarios were investigated with varying aerobic compartment numbers $(1,2,3,4,5,10,20)$ and by turning on/off the IR the effect of the additional stream was observed. $\mathrm{COD}$ and $\mathrm{NH}_{4}-\mathrm{N}$ as indicator parameters of aerobic zone performance were selected and evaluated in each scenario. It has to be mentioned that the compartment numbers are virtual, reflecting the number of CSTR tank in series. If this number increases the flow tends to have plug-flow behaviour. Fig. 2 summarizes the effluent COD values at different compartment numbers. It can be observed that small reactor numbers resulted higher effluent values, application of high number of reactor numbers gave lower values, which means that cascading the system helps in increasing removal efficiency. The effect of IR negligible at high compartment numbers, but if small reactor numbers are applied (in other words: if the flow is close to a CSTR system) the difference in effluent data is higher. In addition, it can be stated that IR helps in organic matter reduction. The explanation could be the dilution effect of the additional flow introduced to the system.

Fig. 3 shows the effluent ammonium concentrations in $\mathrm{mg} / \mathrm{L}$ in scenarios without and with IR at different compartment numbers. The effluent concentration of $\mathrm{NH}_{4}-\mathrm{N}$ at the given conditions in full scale plant was $1.1 \mathrm{mg} / \mathrm{l}$, which is in good accordance with the fact that mixers divides the aerobic volume to 2 or 3 sub-zones. Simulations performed gave us the opportunity to investigate the effect of IR and compartment number without making any modifications at the full scale plant.

Steady-state sensitivity analysis was performed revealing the effect of the small changes in the calibrated parameters on COD and $\mathrm{NH}_{4}-\mathrm{N}$ effluent. The analysis was carried out applying GPS-X 6.5 Analyze function, where the effect of each parameter was evaluated separately. The calibrated values were changed $\pm 10 \%$, as a result the effluent concentrations basically remained unchanged (COD: $<2 \%, \mathrm{NH}_{4}-\mathrm{N}: 5 \%$ ).

Table 2: Effect of IR and compartment number on effluent $\mathrm{NH}_{4}-\mathrm{N}$ concentration.

\begin{tabular}{|l|c|c|c|}
\hline & Influent & Plant effluent & Model effluent \\
\hline COD & 610 & 85 & 94 \\
\hline BOD $_{5}$ & 285 & 22 & 25 \\
\hline $\mathrm{TSS}$ & 345 & 20 & 24 \\
\hline $\mathrm{TN}$ & 92 & 18 & 16 \\
\hline $\mathrm{NH}_{4}-\mathrm{N}$ & 69 & 1.5 & 1.2 \\
\hline
\end{tabular}




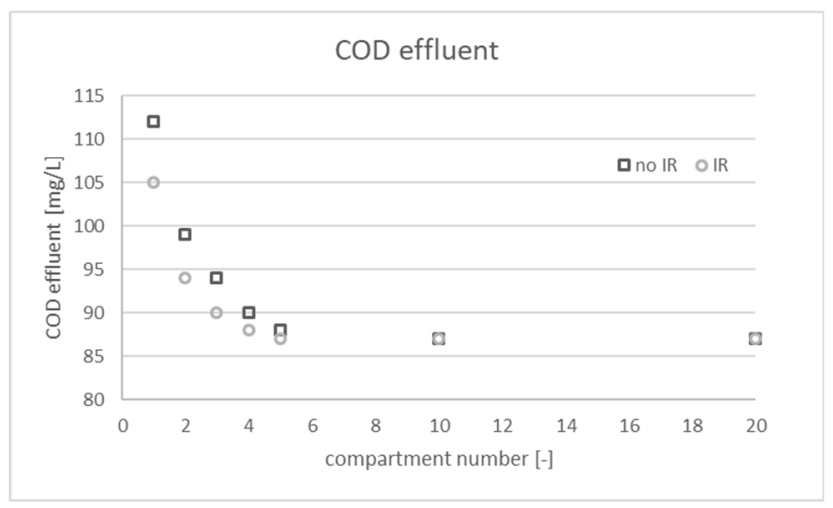

Figure 2: COD effluent using various compartment numbers.

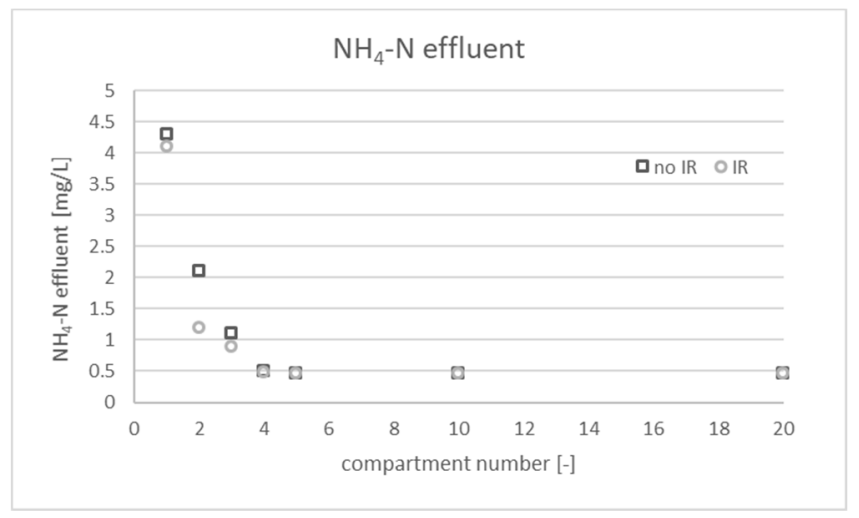

Figure 3: $\mathrm{NH}_{4}-\mathrm{N}$ effluent using various compartment numbers.

Based on the results it can be stated if reactor compartment number increases the effect of IR on reactor model is negligible. In other words, if the aeration tank has plug flow, there is no difference in the effluent ammonium concentrations. It can be also seen that the application of 5, 10 or 20 compartments did not make any changes. If there is only one compartment in aerobic region in the model, the calculation results suggest that there is no effect of IR, which is not in accordance with the full scale plant observations. IR is a surplus flow; thus more energy is available for mixing. If mixing efficiency is enhanced, it also means better oxygen diffusion to the flocs resulting better nitrification. That phenomenon cannot be captured in a simple CSTR tank, since it is completely mixed by definition: the IR flow, which is originated from the same tank as it enters, the completely mixed system cannot be more mixed. Figs 2 and 3 also shows that the IR modifies the virtual compartment number and it shall be reduced if IR is introduced to the system.

\section{CONCLUSIONS}

Introducing IR in a pre-denitrification reactor configuration in wastewater treatment provides nitrate transport to a reactor zone, which is abundant with substrate for heterotrophic denitrifying microorganisms. As a side effect of IR, the surplus flow changes the 
hydrodynamic condition and it increases the mixing and thus the diffusion rate, which helps in organic matter removal and in nitrification. In this research the effect of internal recirculation on reactor model was investigated; the aerobic basin was divided to various virtual compartments and the effluent $\mathrm{COD}$ and $\mathrm{NH}_{4}-\mathrm{N}$ concentration were compared in a system with and without IR. The outcome of the simulations is that if the aeration tank has plug flow, there is no difference in the effluent concentrations, whereas in CSTRs the virtual reactor numbers shall be reduced if IR is present. It can be also observed that cascading the system helped to increase removal efficiency. As a next step of this research numerical fluid dynamic models is to be applied to reveal the actual flow conditions in reactors and our intention is to couple it with mass balance modelling.

\section{ACKNOWLEDGEMENT}

The work was created in commission of the National University of Public Service under the priority project KÖFOP-2.1.2-VEKOP-15-2016-00001 titled 'Public Service Development Establishing Good Governance’ in István Egyed Postdoctoral Program.

\section{REFERENCES}

[1] Esperanza, M., Suidan, M.T., Marfil-Vega, R., Gonzalez, C., Sorial, G.A., McCauley, P. \& Brenner, R., Fate of sex hormones in two pilot-scale municipal wastewater treatment plants: Conventional treatment. Chemosphere, 66(8), pp. 1535-1544, 2007.

[2] Zita, A. \& Hermansson, M., Effects of ionic strength on bacterial adhesion and stability of flocs in a wastewater activated sludge system. Applied and Environmental Microbiology, 60(9), pp. 3041-3048, 1994.

[3] Holloway, T.G. \& Soares, A., Influence of internal fluid velocities and media fill ratio on submerged aerated filter hydrodynamics and process performance for municipal wastewater treatment. Process Safety and Environmental Protection, 114, pp. 179191, 2018.

[4] Olivet, D., Valls, J., Gordillo, M., Freixo, A. \& Sanchez, A., Application of residence time distribution technique to the study of the hydrodynamic behaviour of a full-scale wastewater treatment plant plug-flow bioreactor. Journal of Chemical Technology and Biotechnology, 80(4), pp. 425-432, 2005.

[5] Martin, A.D., Interpretation of residence time distribution data. Chemical Engineering Science, 55(23), pp. 5907-5917, 2000.

[6] Jamadi, M.H. \& Alighardashi, A., A combined method to facilitate the high dispersion modeling for wastewater treatment bioreactors with closed boundaries. Theoretical Foundations of Chemical Engineering, 50(1), pp. 87-91, 2016.

[7] Nguyen, D.D., Ngo, H.H. \& Yoon, Y.S., Effect of internal recycling ratios on biomass parameters and simultaneous reduction of nitrogen and organic matter in hybrid treatment system. Ecological Engineering, 89(1), pp. 24-31, 2016.

[8] García, D., Alcántara, C., Blanco, S., Pérez, R., Bolado, S. \& Muñoz, R., Enhanced carbon, nitrogen and phosphorus removal from domestic wastewater in a novel anoxicaerobic photobioreactor coupled with biogas upgrading. Chemical Engineering Journal, 313, pp. 424-434, 2017.

[9] Makinia, J. \& Wells, S.A., Evaluation of empirical formulae for estimation of the longitudinal dispersion in activated sludge reactors. Water Research, 39(8), pp. 15331542, 2005.

[10] Henze, M., Gujer, W., Mino, T., Matsuo, T., Wentzel, M.C., Marais, G.V.R. \& Van Loosdrecht, M.C., Activated sludge model no. 2d, ASM2d. Water Science and Technology, 39(1), pp. 165-182, 2009. 
[11] Foley, J., De Haas, D., Hartley, K. \& Lant, P., Comprehensive life cycle inventories of alternative wastewater treatment systems. Water Research, 44(5), pp. 1654-1666, 2010.

[12] Myszograj, S., Płuciennik-Koropczuk, E. \& Jakubaszek, A., COD fractions-methods of measurement and use in wastewater treatment technology. Civil and Environmental Engineering Reports, 24(1), pp. 195-206, 2017.

[13] Kujawa, K. \& Klapwijk, B., A method to estimate denitrification potential for predenitrification systems using NUR batch test. Water Research, 33(10), pp. 22912300, 2009.

[14] Huo, J., Jiang, Y., Seaver, W.L., Robinson, R.B. \& Cox, C.D., Statistically based design of wastewater treatment plants (WWTPs) using Monte Carlo simulation of Activated Sludge Model No. 1 (ASM1). World Environmental and Water Resource Congress, 2006.

[15] Phillips, H.M. et al., Wastewater treatment modelling in practice: a collaborative discussion of the state of the art. Water Science and Technology, 59(4), pp. 695-704, 2009.

[16] Rieger, R., Gillot, S., Langergraber, G., Ohtsuki, T., Shaw, A., Takács, I. \& Winkler, S., Guidelines for Using Activated Sludge Models. Scientific and Technical Report No. 22, IWA Publishing: London, 2013. 